\title{
Determinantes dos Custos em Empresas do Setor Moveleiro
}

Adeline Koschel Xavier de Andrade Moreira

Mestrado em Contabilidade pela Faculdade de Economia e Administração de Ribeirão

Preto - FEA-RP/USP

Av. Dr. Maximiliano Baruto, 500. Jd. Universitário. Araras/SP. CEP: 13607-339

E-mail: adelinekoschel@uniararas.br

Cristina Alves da Grasa Oliveira Mestrado em Contabilidade pela Faculdade de Economia e Administração de Ribeirão Preto - FEA-RP/USP Av. Dr. Maximiliano Baruto, 500. Jd. Universitário. Araras/SP.CEP: 13607-339 E-mail: cristinaoliveira@uniararas.br

Paulo Vitor Dias Furlan Doutorado em andamento em Direito Tributário pela Universidad Moron - Argentina Professor da Fundação Hermínio Ometto/UNIARARAS Rua Albert Einstein, 26. Jardim Universitário. Araras/SP. CEP: 13607-331

E-mail: paulovdfurlan@hotmail.com

Eduardo de Brito Mestrado em Contabilidade pela Faculdade de Economia e Administração de Ribeirão Preto - FEA-RP/USP Professor da Fundação Hermínio Ometto/UNIARARAS Av. Dr. Maximiliano Baruto, 500. Jd. Universitário. Araras/SP. CEP: 13607-339 E-mail: Professoreduardodebrito@gmail.com

Luiz Eduardo Gaio Doutorado em Administração pela Faculdade de Economia e Administração de Ribeirão Preto - FEA-RP/USP

Professor da Fundação Hermínio Ometto - FHO/UNIARARAS Avenida Dr. Maximiliano Baruto, 500 - Jd. Universitário/Araras - SP - CEP: 13607-339 E-mail: luiz.gaio@ymail.com

\section{RESUMO}

O objetivo desse artigo é verificar se as indústrias do setor moveleiro das cidades de Araras/SP e Rio Claro/SP fazem uso de determinantes de custos na fase de planejamento estratégico e identificar quais são utilizados. Os determinantes de custos auxiliam as empresas a utilizarem seus recursos de maneira eficaz, diminuindo seus custos, aprimorando o preço de venda e desta maneira aumentando suas vantagens competitivas no mercado. Para isso será realizado um estudo de caso, através de uma pesquisa descritiva, exploratória e qualitativa em três empresas do setor moveleiro, que obtenham o perfil de micro, pequena ou média empresa de acordo com a Lei 
Aplicação do custeio baseado em atividades em uma empresa de serviços rodoviários Edson Roberto Macohon, Jorge Eduardo Scarpin, Wilson Gerigk, Fernanda Castagnolli Domingues, Elvis

Fabio Roman

Complementar 123/2006 que especifica o faturamento da pequena empresa. Esse estudo de caso replica o trabalho de Souza e Mezzomo (2012) realizado em 3 (três) empresas de pequeno porte localizadas na Serra Gaúcha/RS. A coleta de informações e desenvolvimento da pesquisa se deu entre agosto e outubro de 2013. A pesquisa com as empresas foi feita através de entrevista estruturada, com tópicos possibilitando ao entrevistado respostas abertas. Constatou-se que as nomenclaturas teóricas dadas aos determinantes de custos não são conhecidas, porém a utilização ocorre de forma inconsciente não sendo utilizado no planejamento estratégico. Como os determinantes não são amplamente explorados conforme a teoria abordada pelos pesquisadores, consequentemente não são utilizados em sua plenitude como ferramenta da gestão estratégica de custos para obtenção da vantagem competitiva.

Palavras-Chave: Gestão Estratégica de Custos. Determinantes de Custos. Estratégias Competitivas.

\section{Determinants of costs for furniture companies}

\section{ABSTRACT}

This article aims to verify whether the industries of the furniture sector in the cities of Araras / SP and Rio Claro / SP make use of determinants of cost at the strategic planning and identify which are used. The determinants of cost help companies utilize their resources effectively, reducing costs, improving sales price and thus increasing their competitive advantage in the market. For this case study will be conducted through a descriptive, exploratory and qualitative research in three furniture companies, who obtain the profile of micro, small or medium enterprise in accordance with Complementary Law 123/2006 which specifies the billing small business. This case study replicates the work of Souza and Mezzomo (2012) conducted in three small business located in Serra Gaúcha / RS companies. Data collection and research development occurred between August and October 2013. A survey of businesses was made through structured interviews with open threads allowing the interviewee responses. It was found that the theoretical classifications given to the determinants of costs are not known, but the use occurs unconsciously not being used in strategic planning. As the determinants are not widely exploited as the theory used by the researchers, therefore they are not used to its fullest as a tool of strategic cost management to achieve competitive advantage.

Keywords: Strategic Cost Management. Cost Determinants. Competitive Strategies. 
Aplicação do custeio baseado em atividades em uma empresa de serviços rodoviários Edson Roberto Macohon, Jorge Eduardo Scarpin, Wilson Gerigk, Fernanda Castagnolli Domingues, Elvis

Fabio Roman

\section{INTRODUÇÃO}

Os municípios de Araras/SP e Rio Claro/SP, contavam com estimativas em 2013 de 126.391 e 196.821 habitantes, respectivamente, de acordo com Instituto Brasileiro de Geografia e Estatística (IBGE), ambos estão localizados a aproximadamente 173 km da capital paulista, onde se encontra um grande centro comercial e industrial, com grandes empresas dentre elas algumas voltadas para o setor moveleiro.

As empresas, de um modo geral, necessitam de ferramentas que as auxiliem a se manterem de maneira vantajosa em relação aos seus concorrentes. Uma dessas ferramentas é a gestão estratégica de custos (GEC), que de acordo com Silva (1999) "[...] analisa os custos sob um contexto mais amplo, visando desenvolver vantagens competitivas e dar suporte à tomada de decisões [...]". A gestão estratégica de custos, segundo Miotto (2007) "[...] aprofundou os estudos acerca dos determinantes de competitividade, denominando-os como determinantes ou direcionadores de custos".

O mercado competitivo estimula a concorrência, e com isso a rivalidade acirrada entre as empresas, fazendo com que surja a necessidade de utilizarem ações estratégicas inovadoras. Os determinantes de custos farão com que a empresa utilize seus recursos de maneira agregar valor econômico, que é segundo Barney e Hesterly (2011) "[...] simplesmente a diferença entre os benefícios percebidos obtidos por um cliente que compra produto/serviços de uma empresa e custo econômico total desses produtos/serviços", tornando-se mais competitivas.

Mediante o exposto, surge o problema de pesquisa: as indústrias moveleiras fazem uso de determinantes de custos na fase do planejamento estratégico e, em caso positivo, quais são eles?

O presente estudo analisou e descreveu determinantes de custo utilizados pelas empresas do setor moveleiro de Araras/SP e Rio Claro/SP, comparando-os com as obras literárias. O trabalho está estruturado em cinco partes: introdução, referencial teórico sobre assunto, metodologia, análise de dados coletados e considerações finais. 
Aplicação do custeio baseado em atividades em uma empresa de serviços rodoviários Edson Roberto Macohon, Jorge Eduardo Scarpin, Wilson Gerigk, Fernanda Castagnolli Domingues, Elvis

Fabio Roman

\section{REFERENCIAL TEÓRICO}

\subsection{Vantagem Competitiva}

A concorrência, causada pelo crescente aumento de indústrias e pela exigibilidade do mercado, faz com que as empresas utilizem estratégias de competição capazes de as manterem ativas. Essas estratégias devem estar constantemente atualizadas de acordo com a realidade que a empresa está inserida, pois caso contrário não poderá atingir seus objetivos. A vantagem competitiva está ligada à necessidade de obtenção de requisitos e desenvolvimento de atributos que propicie melhores condições de competir em relação às condições dos concorrentes.

Segundo Oliveira (2011), "[...] o rumo mais adequado para futura estratégia empresarial será aquele em que a empresa possa distinguir-se, favoravelmente, de suas concorrentes [...] se uma empresa quiser ser eficaz no mercado ela deve ter significativa vantagem competitiva."

De acordo com Porter (1989), a vantagem competitiva se divide em dois tipos: liderança de custo e diferenciação.

\subsubsection{Liderança de Custo}

Porter (1989) expõe que normalmente os custos das atividades nas empresas são determinados em sequência, comparando de forma simples apenas os custos de matéria-prima e salários de mão-de-obra, sem reconhecer a relação entre as atividades que podem afetar o custo. Isso ocorre, pois muitos dos condutores importantes do comportamento do custo são ignorados por inexistência de uma metodologia sistemática. A liderança de custo analisa a cadeia de valores dentro das atividades, pois cada atividade tem a sua estrutura de custo. Desta maneira, a empresa pode compreender o comportamento do custo de uma forma total e ampla, que guie a busca de uma vantagem de custo sustentável que contribua para a formulação de estratégia competitiva, pois assim, terá um valor menor que o custo da concorrência, sem prejudicar a qualidade do produto e o serviço ao cliente. 
Aplicação do custeio baseado em atividades em uma empresa de serviços rodoviários Edson Roberto Macohon, Jorge Eduardo Scarpin, Wilson Gerigk, Fernanda Castagnolli Domingues, Elvis

Fabio Roman

\subsubsection{Diferenciação}

A diferenciação significa criar qualidades únicas para o produto, pretendendo atender clientes com necessidades especifícas. Na visão Porter (2004) "[...] é diferenciar o produto ou serviço oferecido pela empresa, criando algo que seja considerado único no âmbito de toda a indústria.". Essa diferenciação pode se dar através de característica tangível (tecnologia e design, etc...) e intangível (imagem de marca, status, etc...).

A estratégia de liderança de custo não anula a estratégia de diferenciação, uma é complemento da outra, pois ao optar por uma posição de líder de custo, uma empresa pode tornar-se uma líder de produtos diferenciados para público especifícos. Assim, uma estratégia não é melhor que a outra, mas a combinação delas fornece à empresa uma vantagem competitiva sustentável.

\subsection{Gestão Estratégica de Custos}

O aumento progressivo da competitividade entre as empresas fez com que a contabilidade de custo tradicional utilizada por décadas, que considerava apenas o volume de produção para apuração dos custos, ficasse inadequada para tomada de decisão. A necessidade de um novo tratamento e visão dos custos incorridos nas empresas deu surgimento à gestão estratégica de custos (GEC) que auxilia as empresas a se manterem de maneira sustentável no mercado.

A gestão estratégica de custo (GEC), segundo Shank e Govindarajan (1997, p. 4), "é uma análise de custos vista sob um contexto mais amplo, em que os elementos estratégicos tornam-se mais conscientes, explícitos e formais". Desta maneira, a GEC possui um perfil pró-ativo centrado no processo de gestão empresarial, e criando um sistema de informação contábil que oferece suporte às decisões estratégicas dos gestores.

Para entender a preparação e a análise da GEC, devem se verificar três temas chaves, de acordo com Shank e Govindarajan (1997), que são: a análise da cadeia de valor; a análise do posicionamento estratégico e a análise dos determinantes de custos. 
Aplicação do custeio baseado em atividades em uma empresa de serviços rodoviários Edson Roberto Macohon, Jorge Eduardo Scarpin, Wilson Gerigk, Fernanda Castagnolli Domingues, Elvis

Fabio Roman

a) Cadeia de valor: é a identificação e a exploração de elos da empresa que se inicia nas fontes de matéria-prima até o produto acabado para os clientes.

b) Posicionamento estratégico: tratam as oportunidades externas do ambiente da empresa, os recursos disponíveis, além de planejar metas e ações para realizálos.

c) Determinantes de custos: abordam os aspectos que precedem o início da produção e exercem influência nas condições e formas de organizar a produção, as quais se relacionam entre si de forma complexa.

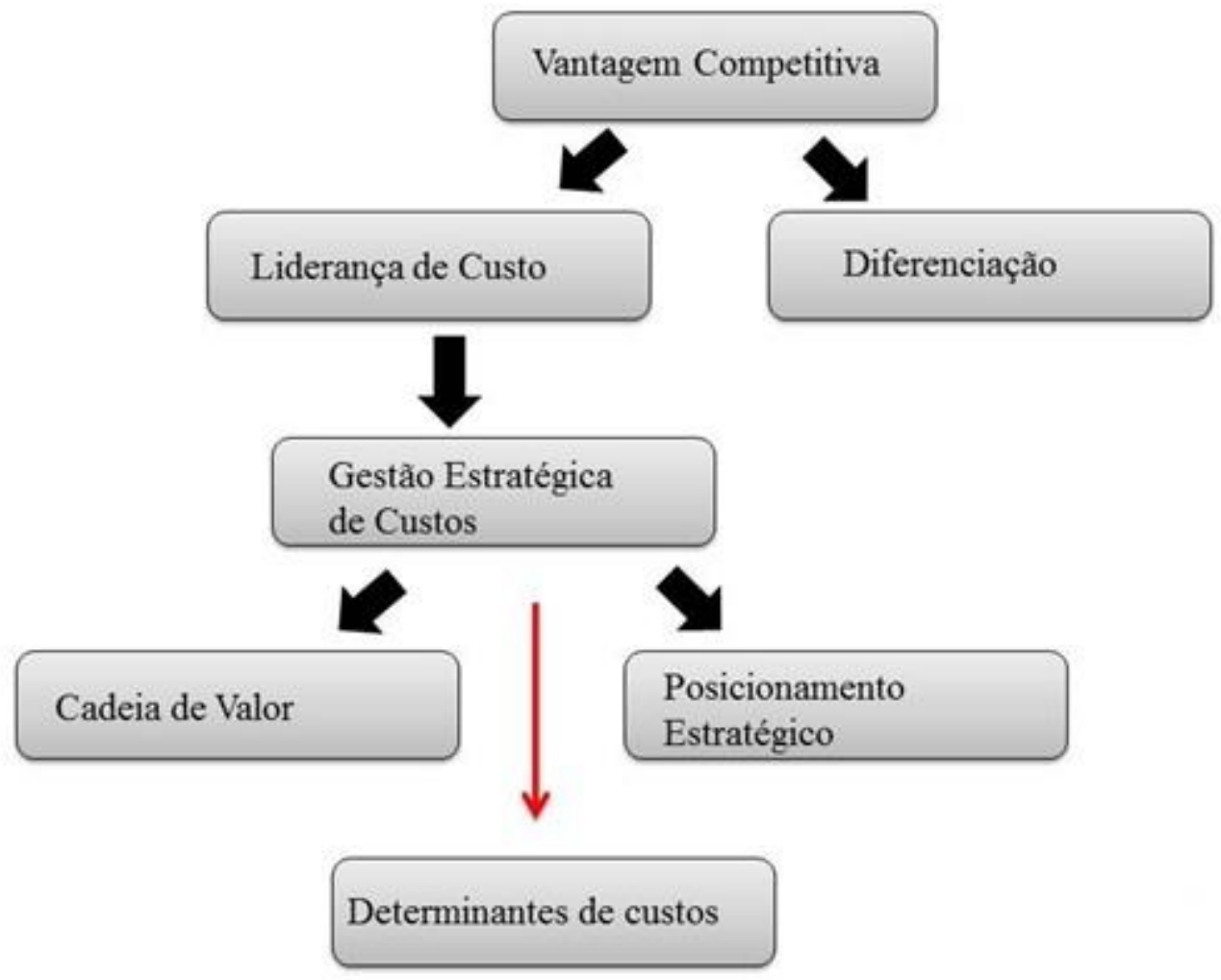

Fonte: elaborado pelos autores, baseado em Oliveira (2011), Porter (1989), Porter (2004), Shank e Govindarajan (1997). 
Aplicação do custeio baseado em atividades em uma empresa de serviços rodoviários Edson Roberto Macohon, Jorge Eduardo Scarpin, Wilson Gerigk, Fernanda Castagnolli Domingues, Elvis

Fabio Roman

\subsection{Determinantes dos Custos}

Determinantes de custos são abordados por diversos autores com nomenclaturas distintas, por Brimson (1996) como geradores de custos, Shank e Govindarajan (1997) como direcionadores de custos e Porter (1989) condutores de custos. Segundo Mário (2003), o termo adequado a ser utilizado é o determinante de custo, pois é este que melhor define os fatores causadores de custo, não apresentando em sua nomenclatura a possibilidade de uma segunda interpretação. De maneira semelhante, Costa e Carneiro (2014) defendem que "[...]" os determinantes de custos são as causas reais dos custos, em outras palavras, a raiz dos custos, ou ainda, os elementos que estão no cerne e provocam a existência de um determinado custo, sua essência". Por outro lado, os direcionadores são mais utilizados na alocação do custo ao produto, ou seja, após o consumo do recurso ele é utilizado para indicar em qual atividade/produto o custo deverá ser atribuído.

O Quadro 1 demonstra de forma sucinta as principais diferenças entre direcionadores e determinantes de custos.

\begin{tabular}{|c|c|}
\hline DETERMINANTES DE CUSTOS & DIRECIONADORES DE CUSTOS \\
\hline Estabelece a geração de custos & Utilizado para alocação de custos \\
\hline $\begin{array}{c}\text { Fator que determina de forma antecipada o nível e } \\
\text { estrutura da futura ocorrência dos custos. }\end{array}$ & $\begin{array}{c}\text { Medidas de desempenho utilizadas para } \\
\text { atribuir os custos às atividades e os produtos. }\end{array}$ \\
\hline $\begin{array}{c}\text { Pré-estabelecidos em fase anterior à ocorrência } \\
\text { das atividades (fase de planejamento). }\end{array}$ & $\begin{array}{c}\text { Realizados durante as atividades, momento } \\
\text { em que há a geração dos custos (fase de } \\
\text { execução). }\end{array}$ \\
\hline
\end{tabular}

Quadro 1 - Diferenciação entre direcionadores e determinantes de custos Fonte: Souza e Mezzomo (2012, p. 135)

As causas dos custos se dividem em duas grandes classes sendo classificados em determinantes de custos estruturais e determinantes de custos operacionais. Posteriormente, para melhor compreensão, serão apresentados de forma mais abrangente: 
Aplicação do custeio baseado em atividades em uma empresa de serviços rodoviários Edson Roberto Macohon, Jorge Eduardo Scarpin, Wilson Gerigk, Fernanda Castagnolli Domingues, Elvis

Fabio Roman

\subsubsection{Determinantes de Custos Estruturais}

Determinantes de custos estruturais, segundo Souza e Mezzomo (2012), "refletem as opções estratégicas primárias da empresa, levando em consideração sua estrutura econômica [...]", logo os elementos que determinam a estrutura organizacional ressaltam as decisões de investir e desinvestir em longo prazo. Nessa pesquisa serão abordados alguns dos determinantes considerados estruturais, conforme tratado por Souza e Mezzomo (2012), são eles: tecnologia, economia de escala, modelo de gestão, estrutura de capitais, grau de verticalização, experiência e escopo.

Tecnologia: $\mathrm{Na}$ visão de Hayes et al. (2008), a tecnologia pode ocasionar vantagens de duas formas: permite uma atuação operacional superior na medida que for aplicada na estratégia competitiva da empresa como no custo, velocidade, confiança, etc.; proporcionam a elaboração de produto mais rápido, eficiente e eficaz. Ainda aludindo à tecnologia, conforme Diehl, Miotto e Souza (2010), tem-se que a mesma "[...] pode diminuir o custo com o pessoal, aumentar a escala de produção, melhorar a qualidade dos produtos ou serviços, dentre outros fatores." Todavia, se a tecnologia for utilizada de forma inapropriada, pode acarretar custos extras.

Economia de escala: Ocorre quando, segundo Hitt et al. (2008), " [...] a quantidade de produtos produzidos em um determinado período aumenta, o custo para fabricar cada unidade diminui. " É um imprescindível determinante de custo estrutural, pois consiste em dimensionar a estrutura empresarial do modo mais otimizado possível, diluindo melhor os custos pelo volume produzido ou serviço prestado. Entretanto, Porter (1989, p. 65) sinaliza quanto ao equívoco por vezes feito entre economia de escala e economia de utilização e explica que "confundir utilização da capacidade com economia de escala pode levar uma empresa à falsa conclusão de que seus custos continuaram caindo, se ela expandir a capacidade uma vez plena a sua capacidade existente. "

Modelo de gestão: é considerado determinante de custo visto que pode afetar a estrutura administrativa e cultural da organização, assim determina como a empresa monitora suas atividades, tanto no aspecto operacional como econômico, evidenciando em qual nível a tomada de decisão é realizada. 
Aplicação do custeio baseado em atividades em uma empresa de serviços rodoviários Edson Roberto Macohon, Jorge Eduardo Scarpin, Wilson Gerigk, Fernanda Castagnolli Domingues, Elvis

Fabio Roman

Estrutura de capitais: Como descrito por ludícibus (1998), a verificação da estrutura de capitais busca demonstrar a posição do capital próprio com relação ao capital de terceiros apontando a dependência da empresa quanto ao capital de terceiros.

Grau de verticalização: Do ponto de vista de Diehl, Miotto e Souza (2010), "[...] estabelece em que medida o compartilhamento de recursos corporativos poderá ser realizado, bem como trazer sinergias pelo encaixe de atividades dentro de uma mesma organização. ". O grau de verticalização viabiliza a independência de terceiros, maior autonomia e domínio sobre tecnologia própria, em contrapartida maior investimento, menor flexibilidade e aumento da estrutura da empresa.

Experiência: Está associado com o conhecimento adquirido ao longo do tempo da organização, das pessoas que a constituem e com a melhoria das atividades por elas realizadas.

Escopo: Como descrito por Porter (1989), "Um escopo amplo pode permitir que uma empresa explore os benefícios da execução interna de um maior número de atividades". Assim, a combinação de um conjunto de produtos ou serviços variados que utilize uma mesma estrutura é elemento estratégico que deve ser planejado de acordo com o mercado e com o melhor proveito da estrutura empresarial.

\subsubsection{Determinantes de Custos Operacionais}

Silva (1999) alega que determinantes de custos operacionais "[...] constituem todos os fatores associados à execução do projeto, [...] os quais visam analisar a realização dos custos e a capacidade de executar bem. "Nessa pesquisa serão abordados alguns dos determinantes considerados operacionais, conforme tratado por Souza e Mezzomo (2012) são eles: grau de utilização da capacidade, grau de complexidade, qualidade, comprometimento, competência e habilidades, capacidade de aprendizagem e relação na cadeia de valor.

Grau da utilização da capacidade: Miotto (2007) afirma que "está relacionado à escala. [...] quanto mais a empresa produz, melhor será a diluição dos seus gastos 
Aplicação do custeio baseado em atividades em uma empresa de serviços rodoviários Edson Roberto Macohon, Jorge Eduardo Scarpin, Wilson Gerigk, Fernanda Castagnolli Domingues, Elvis

fixos. " Portanto, o grau da utilização da capacidade está associado com o uso da unidade produtiva e ligado diretamente a volume de produção.

Grau de complexidade: Para Miotto (2007), "é um determinante de custo ligado ao determinante estrutural escopo. Na medida em que aumenta o escopo de produtos ou serviços de uma empresa, pode aumentar a complexidade do seu processo [...]". Ainda, o grau de complexidade pode estar associado às particularidades de um produto/serviço.

Qualidade: está ligada ao nível de excelência e conformidade dos produtos e procedimentos da organização, onde, quanto maior a qualidade menor serão as perdas. Assim a qualidade cria a imagem da empresa que será percebida pelo mercado e seus clientes.

Comprometimento, capacidade de aprendizagem, competência e habilidades: $\mathrm{Na}$ opinião de Miotto (2007) "estão relacionados com as políticas de recursos humanos da empresa, e, [...] são fundamentais para sua solidificação ao longo do tempo e para sua continuidade. " Esses determinantes podem aumentar a eficiência da produção e diminuir as imperfeições e desperdícios, consequentemente atenuar os custos.

Relação na cadeia de valor: No dizer de Diehl, Miotto e Souza (2010), "[...] expressa o relacionamento da empresa desde os fornecedores até os consumidores finais, buscando extrair, dessas relações, as melhores formas de otimizar seus resultados e de seus clientes. "Ressaltando que o relacionamento da empresa na cadeia de valor pode estender-se aos concorrentes diretos.

\section{METODOLOGIA}

A pesquisa foi desenvolvida em 3 (três) empresas do setor moveleiro, localizado nas cidades de Araras e Rio Claro, ambas situadas no estado de São Paulo.

O presente trabalho é um estudo de caso, que segundo Benbasat, Goldstein e Mead (1987, apud Maçada, Feldens e Santos, 2007, p. 4) "é útil quando a pesquisa tem a intenção de aprofundar os conhecimentos sobre uma realidade para a construção de 
Aplicação do custeio baseado em atividades em uma empresa de serviços rodoviários Edson Roberto Macohon, Jorge Eduardo Scarpin, Wilson Gerigk, Fernanda Castagnolli Domingues, Elvis

Fabio Roman

uma proposição teórica". Através do estudo de caso, pode-se conseguir informações mais específicas para formular uma possível realidade, pois em estudo de caso únicos pode haver exceções e não uma realidade.

Realizou-se uma pesquisa exploratória, a qual "[...] tem como principal finalidade desenvolver, esclarecer e modificar conceitos e ideias, tendo em vista, a formulação de problemas mais precisos ou hipóteses pesquisáveis para estudo posteriores (GIL, 1999, p. 43) ". A pesquisa exploratória fornece embasamento para desenvolver o projeto, pois os estudos de casos necessitam de análises detalhadas que apenas uma pesquisa desse nível pode fornecer.

A pesquisa classifica-se também descritiva, pois enumera as propriedades de uma determinada população. Após a enumeração das propriedades deu-se a análise relacionando as práticas das empresas com as teorias existentes sobre 0 assunto.

$O$ estudo é qualitativo, pois auxilia a indicar o funcionamento de determinantes de custos dentro da empresa, ajudando a teorizar a realidade da mesma. De acordo com Richardson (1999, p. 80), "podem descrever a complexidade de determinado problema [...] contribuir no processo de mudança de determinado grupo e possibilitar [...] o entendimento das particularidades do comportamento [...]".

Como o presente estudo de caso replica o trabalho de Souza e Mezzomo (2012), o qual considera uma amostra de 3 (três) empresas do setor moveleiro, foi considerada no presente uma amostra composta por 3 (três) empresas desse setor, porém localizadas nas cidades de Araras/SP e Rio Claro/SP, classificadas com base na Lei Complementar 123/ 2006, como micro, pequeno ou médio porte.

Algumas das empresas, do setor moveleiro de Araras/SP e Rio Claro/SP, foram convidadas e esclarecidas sobre o objetivo desse estudo e aquelas que aceitaram participar, responderam os devidos questionamentos necessários para o desenvolvimento do trabalho.

O processo de contato com as empresas, coleta de informações e desenvolvimento da pesquisa se deu entre agosto e outubro de 2013. A pesquisa com as empresas foi feita através de entrevista estruturada, com tópicos possibilitando ao entrevistado respostas abertas. 
Aplicação do custeio baseado em atividades em uma empresa de serviços rodoviários Edson Roberto Macohon, Jorge Eduardo Scarpin, Wilson Gerigk, Fernanda Castagnolli Domingues, Elvis

Fabio Roman

A análise de dados foi feita de forma individual por empresa, através de interpretação dos dados e informações coletadas, expondo as respostas dos questionamentos e confrontando-as com as bases literárias pesquisadas.

\section{ANÁLISE DE DADOS}

A pesquisa foi desenvolvida em 3 (três) empresas do setor moveleiro, sendo 2 (duas) localizadas na cidade de Araras e 1 (uma) na cidade de Rio Claro, ambas situadas no estado de São Paulo. As empresas serão tratadas por nomes fictícios, para manter o sigilo das mesmas, sendo nomeadas como: Empresa A, Empresa $B$ e Empresa C.

\begin{tabular}{|c|c|c|c|c|c|}
\hline & $\begin{array}{c}\text { Atuação de } \\
\text { mercado }\end{array}$ & Produtos & Faturamento & Porte & Funcionários \\
\hline Empresa A & 45 anos & 640 & $\mathrm{R} \$ 20$ milhões & Médio & 190 \\
\hline Empresa B & 13 anos & 380 & $\mathrm{R} \$ 8,5$ milhões & Médio & 90 \\
\hline Empresa C & 3 anos & 50 & $\mathrm{R} \$ 245$ mil & Micro & 8 \\
\hline
\end{tabular}

Quadro 2 - Características das empresas consideradas no estudo Fonte: Dados da pesquisa.

a) Empresa A: Atua no mercado nacional há 45 anos; com um quadro de 190 funcionários, a empresa trabalha com linhas de produtos, totalizando 640 produtos diferentes, composto por mobiliário corporativo, call center, consoles, conjunto escolar, cadeiras, longarinas. Com um faturamento bruto anual de aproximadamente $R \$ 20$ milhões em 2012, é considerada uma empresa de médio porte com base na Lei complementar 123/2006. A entrevista foi realizada com o analista de venda, que foi indicado pela diretoria por já ter percorrido vários departamentos da empresa, formado em administração e cursando pósgraduação em controladoria e finanças, trabalha na empresa e no setor moveleiro há 8 anos, sem experiência anterior. 
Aplicação do custeio baseado em atividades em uma empresa de serviços rodoviários Edson Roberto Macohon, Jorge Eduardo Scarpin, Wilson Gerigk, Fernanda Castagnolli Domingues, Elvis

b) Empresa B: Atua no mercado nacional há 13 anos; com um quadro de 90 funcionários, a empresa produz 380 produtos diferentes, composto por mobiliário corporativo, recepção, gerência, diretoria, reunião e staff. Com um faturamento bruto anual de aproximadamente $\mathrm{R} \$ 8,5$ milhões em 2012, é considerada uma empresa de médio porte com base na Lei complementar 123/2006. A entrevista foi realizada com o diretor administrativo, formado em administração, trabalha no setor moveleiro há 22 anos, sendo 10 anos na empresa entrevistada.

c) Empresa C: Atuando no mercado nacional há 3 anos; com um quadro de 8 funcionários, a empresa trabalha com fabricação de produtos planejados, totalizando 50 produtos diferentes, composto por banheiro, cozinha, escritório, closets, dormitórios, decks, escadas, home office, mesas de centro, painéis, venezianas e portas, etc. Com um faturamento bruto anual de aproximadamente $\mathrm{R} \$ 245$ mil em 2012 e é considerada uma micro empresa com base na Lei complementar 123/2006. A entrevista foi realizada com o proprietário, o qual não possui ensino superior, tendo 21 anos que atua no mercado moveleiro, e criou a empresa há 3 anos.

\subsection{Análise dos Determinantes de Custos Estruturais}

Os determinantes de custos estruturais foram abordados na entrevista de forma individualizada a fim de obter os dados necessários para a formulação da pesquisa, conforme descritos no Quadro 3.

O determinante de custo estrutural de tecnologia é utilizado com maior frequência nas empresas $A$ e $B$, onde o grande número de produtos que compõem 0 escopo exige que as empresas sempre busquem novas tecnologias para padronizar seus produtos, maximizar a produção, obter qualidade, diminuir custos com mão de obra. Já na empresa $C$, por possuir mão de obra artesanal e escopo composto por um menor número de produtos, utiliza a tecnologia com menor frequência.

Nas empresas envolvidas na pesquisa a produção é realizada conforme pedidos, evitando despesas com estoques ociosos. A empresa $C$, fabricante de móveis planejados, possui estoque de matéria-prima composto apenas de material por "sobras" 
Aplicação do custeio baseado em atividades em uma empresa de serviços rodoviários Edson Roberto Macohon, Jorge Eduardo Scarpin, Wilson Gerigk, Fernanda Castagnolli Domingues, Elvis

Fabio Roman

de pedidos anteriores. As empresas A e B, provavelmente, por serem empresas de médio porte, para melhor gerir os setores adotam um modelo de gestão descentralizado com hierarquia vertical oferecendo, aos funcionários, plano de carreira. O mesmo não ocorre na empresa $\mathrm{C}$, por ser uma microempresa, o proprietário é o responsável pelas principais atividades de controle adotando o modelo de gestão centralizado.

\begin{tabular}{|c|c|c|c|}
\hline $\begin{array}{l}\text { Determinantes } \\
\text { Estruturais }\end{array}$ & Empresa A & Empresa B & Empresa C \\
\hline Tecnologia & $\begin{array}{l}\text { Utilizam máquinas, pouca } \\
\text { utilização de mão de obra } \\
\text { artesanal, reduzindo assim, } \\
\text { custo com mão de obra, } \\
\text { perdas e aumentando } \\
\text { padronização dos produtos. }\end{array}$ & $\begin{array}{l}\text { Utilizam máquinas com } \\
\text { tecnologia avançada } \\
\text { que reduz custo com } \\
\text { manutenção e mão de } \\
\text { obra, e tendo uma } \\
\text { maior qualidade e } \\
\text { facilita a produção. }\end{array}$ & $\begin{array}{l}\text { Utiliza mão de obra artesanal, com } \\
\text { pouco maquinário tendo pouco custo } \\
\text { com manutenção. }\end{array}$ \\
\hline $\begin{array}{l}\text { Economia de } \\
\text { escala }\end{array}$ & $\begin{array}{l}\text { A produção é realizada } \\
\text { conforme os pedidos, } \\
\text { mantendo estoques de } \\
\text { produtos acabados apenas } \\
\text { para contratos que exigem } \\
\text { estoque mínimo. } \\
\end{array}$ & $\begin{array}{l}\text { A produção é realizada } \\
\text { conforme pedidos, } \\
\text { mantendo estoque } \\
\text { apenas de matéria- } \\
\text { prima. }\end{array}$ & $\begin{array}{l}\text { A produção é realizada conforme } \\
\text { encomendas, não havendo estoque } \\
\text { de produtos acabados e o estoque } \\
\text { de matéria-prima é composto apenas } \\
\text { por "sobras" de pedidos anteriores. }\end{array}$ \\
\hline $\begin{array}{l}\text { Modelo de } \\
\text { gestão }\end{array}$ & $\begin{array}{l}\text { Adota o modelo de gestão } \\
\text { descentralizada, hierarquia } \\
\text { vertical, possuindo plano de } \\
\text { carreira. }\end{array}$ & $\begin{array}{l}\text { Adota o modelo de } \\
\text { gestão descentralizada, } \\
\text { hierarquia vertical, } \\
\text { possuindo plano de } \\
\text { carreira. }\end{array}$ & $\begin{array}{c}\text { Adota o modelo de gestão } \\
\text { centralizado, o proprietário é } \\
\text { responsável por todas as atividades } \\
\text { de controle. }\end{array}$ \\
\hline $\begin{array}{l}\text { Estrutura de } \\
\text { capitais }\end{array}$ & Utiliza Capital próprio. & $\begin{array}{c}\text { Utiliza Capital próprio, e } \\
\text { de terceiros. }\end{array}$ & Utiliza Capital próprio. \\
\hline $\begin{array}{c}\text { Grau de } \\
\text { verticalização }\end{array}$ & $\begin{array}{l}\text { Atua apenas na fabricação, } \\
\text { sendo o transporte e setor } \\
\text { fiscal terceirizado. }\end{array}$ & $\begin{array}{l}\text { Atua na fabricação e no } \\
\text { transporte da } \\
\text { mercadoria, } \\
\text { terceirizando apenas o } \\
\text { setor fiscal. } \\
\end{array}$ & $\begin{array}{l}\text { Atua na fabricação e no transporte } \\
\text { da mercadoria, terceirizando o setor } \\
\text { fiscal e recursos humanos. }\end{array}$ \\
\hline Experiência & $\begin{array}{l}\text { Mantem funcionários antigos } \\
\text { na produção, pois auxiliam } \\
\text { no treinamento de novos } \\
\text { funcionários. }\end{array}$ & $\begin{array}{l}\text { Mantem funcionários } \\
\text { antigos que na maioria } \\
\text { ocupam cargos de } \\
\text { chefia, orientando } \\
\text { melhor o setor } \\
\text { operacional. }\end{array}$ & $\begin{array}{l}\text { Mantem funcionários antigos na } \\
\text { produção, pois auxiliam no } \\
\text { treinamento de novos funcionários. }\end{array}$ \\
\hline Escopo & $\begin{array}{c}\text { Produz } 640 \text { produtos } \\
\text { diferentes, sendo que } \\
\text { utilizam as mesmas } \\
\text { máquinas no processo } \\
\text { produtivo, minimizando } \\
\text { custos. } \\
\end{array}$ & $\begin{array}{c}\text { Produz } 380 \text { produtos } \\
\text { diferentes, sendo que } \\
\text { utilizam as mesmas } \\
\text { máquinas no processo } \\
\text { produtivo, minimizando } \\
\text { custos. } \\
\end{array}$ & $\begin{array}{c}\text { Produz } 50 \text { produtos diferentes, sendo } \\
\text { que utilizam as máquinas para } \\
\text { procedimentos básicos para a } \\
\text { fabricação de todos os produtos } \\
\text { minimizando custos. }\end{array}$ \\
\hline
\end{tabular}

Quadro 3 - Determinantes de custos estruturais Fonte: Dados da pesquisa. 
Aplicação do custeio baseado em atividades em uma empresa de serviços rodoviários Edson Roberto Macohon, Jorge Eduardo Scarpin, Wilson Gerigk, Fernanda Castagnolli Domingues, Elvis

Fabio Roman

\subsection{Análise dos Determinantes de Custos Operacionais}

Os determinantes de custos operacionais, assim com os determinantes de custos estruturais, também foram abordados na entrevista de forma individualizada a fim de obter os dados necessários para a formulação da pesquisa, conforme descritos no Quadro 4.

As empresas A e B não utilizam sua capacidade total, o grau de utilização de capacidade oscila de acordo com as vendas. Na empresa $\mathrm{C}$, o grau de utilização de capacidade é total, a produção é realizada conforme a capacidade do espaço e ao número de funcionários. Além da semelhança no grau de utilização de capacidade, as empresas $A$ e $B$ utilizam os mesmos maquinários para fabricação de vários produtos, dessa maneira o grau de complexidade é baixo, oposto da empresa $\mathrm{C}$, que tem um alto grau de complexidade por fabricar produtos com características específicas.

Dentre os determinantes de custos operacionais, a qualidade foi o que apresentou maior destaque nas empresas, considerado como um fator primordial, uma vez que pretendem atingir a satisfação cliente. Para atingir tal objetivo, as empresas efetuam trocas de produtos danificados e todos os danos ocorridos na produção ou nos transportes são arcados pelas empresas. A qualidade necessita de um quadro de funcionários comprometidos, capacitados, competentes e habilidosos, assim as empresas entrevistadas disponibilizam cursos variados, treinamentos constantes, planos de carreira e avaliação de desempenho, designando a função mais adequada ao desempenho dos funcionários. 
Aplicação do custeio baseado em atividades em uma empresa de serviços rodoviários Edson Roberto Macohon, Jorge Eduardo Scarpin, Wilson Gerigk, Fernanda Castagnolli Domingues, Elvis

Fabio Roman

\begin{tabular}{|c|c|c|c|}
\hline $\begin{array}{l}\text { Determinantes } \\
\text { Operacionais }\end{array}$ & Empresa A & Empresa B & Empresa C \\
\hline $\begin{array}{l}\text { Grau de utilização } \\
\text { da capacidade }\end{array}$ & $\begin{array}{l}\text { Utiliza } 50 \% \text { da capacidade, } \\
\text { pois a produção é realizada } \\
\text { de acordo com as vendas. }\end{array}$ & $\begin{array}{c}\text { Utiliza } 70 \% \text { da } \\
\text { capacidade, pois a } \\
\text { produção é realizada de } \\
\text { acordo com as vendas. }\end{array}$ & $\begin{array}{l}\text { Utiliza da capacidade } \\
\text { total, pois a produção é } \\
\text { realizada de acordo com } \\
\text { espaço e o número de } \\
\text { funcionários. }\end{array}$ \\
\hline $\begin{array}{c}\text { Grau de } \\
\text { complexidade }\end{array}$ & $\begin{array}{c}\text { Baixo grau de } \\
\text { complexidade, pois apesar } \\
\text { do grande número de } \\
\text { produtos, utilizam os } \\
\text { mesmos maquinários. }\end{array}$ & $\begin{array}{c}\text { Baixo grau de } \\
\text { complexidade, pois } \\
\text { apesar do grande } \\
\text { número de produtos, } \\
\text { utilizam os mesmos } \\
\text { maquinários. }\end{array}$ & $\begin{array}{c}\text { Alto grau de } \\
\text { complexidade, por se } \\
\text { tratar de móveis } \\
\text { planejados com } \\
\text { características } \\
\text { específicas. }\end{array}$ \\
\hline Qualidade & $\begin{array}{l}\text { Possui um setor } \\
\text { responsável pela } \\
\text { qualidade, garantindo a } \\
\text { satisfação dos clientes, } \\
\text { realizando as trocas de } \\
\text { produtos danificados. }\end{array}$ & $\begin{array}{l}\text { Trata qualidade como } \\
\text { fator primordial, já que a } \\
\text { qualidade é um } \\
\text { diferencial dos seus } \\
\text { produtos, realiza trocas } \\
\text { de produtos danificados. }\end{array}$ & $\begin{array}{l}\text { Mantem a qualidade dos } \\
\text { produtos através de } \\
\text { controle feito pelo } \\
\text { proprietário em todas as } \\
\text { etapas do processo, os } \\
\text { danos ocorridos na } \\
\text { produção e transporte são } \\
\text { arcados pela empresa. }\end{array}$ \\
\hline Comprometimento & $\begin{array}{c}\text { Busca o comprometimento } \\
\text { dos funcionários } \\
\text { oferecendo plano de } \\
\text { carreira. }\end{array}$ & $\begin{array}{l}\text { Busca o } \\
\text { comprometimento dos } \\
\text { funcionários oferecendo } \\
\text { agradável ambiente de } \\
\text { trabalho e participação } \\
\text { de lucros obtidos. }\end{array}$ & $\begin{array}{c}\text { Busca o } \\
\text { comprometimento dos } \\
\text { funcionários oferecendo } \\
\text { um bom ambiente de } \\
\text { trabalho, e boa } \\
\text { renumeração. }\end{array}$ \\
\hline $\begin{array}{l}\text { Capacidade de } \\
\text { Aprendizagem }\end{array}$ & $\begin{array}{c}\text { Disponibiliza cursos } \\
\text { variados entre eles inglês e } \\
\text { específicos de cada área. }\end{array}$ & $\begin{array}{c}\text { Treinamentos } \\
\text { constantes para o } \\
\text { aperfeiçoamento de } \\
\text { cada função. }\end{array}$ & $\begin{array}{l}\text { Cursos da área para o } \\
\text { aperfeiçoamento de cada } \\
\text { função. }\end{array}$ \\
\hline $\begin{array}{l}\text { Competência e } \\
\text { habilidades }\end{array}$ & $\begin{array}{c}\text { Realiza avaliação de } \\
\text { desempenho para verificar } \\
\text { as competências e } \\
\text { habilidades, designando } \\
\text { funções de acordo com } \\
\text { suas aptidões. }\end{array}$ & $\begin{array}{l}\text { Realiza avaliação de } \\
\text { desempenho para } \\
\text { verificar as } \\
\text { competências e } \\
\text { habilidades, designando } \\
\text { funções de acordo com } \\
\text { suas aptidões. }\end{array}$ & $\begin{array}{c}\text { A percepção das } \\
\text { competências e } \\
\text { habilidades ocorre por } \\
\text { meio da observação do } \\
\text { proprietário. }\end{array}$ \\
\hline $\begin{array}{l}\text { Relação na cadeia } \\
\text { de valor }\end{array}$ & $\begin{array}{l}\text { Mantem relação com toda a } \\
\text { cadeia de valor, inclusive } \\
\text { com alguns concorrentes. }\end{array}$ & $\begin{array}{l}\text { Mantem relação com } \\
\text { fornecedores e clientes. }\end{array}$ & $\begin{array}{l}\text { Mantem relação com } \\
\text { fornecedores e clientes. }\end{array}$ \\
\hline
\end{tabular}

Quadro 4 - Determinantes de custos operacionais Fonte: Dados da pesquisa.

\subsection{Análise Geral}

Embora a terminologia "Determinantes de Custos" não seja de conhecimento dos pesquisados, eles demonstram conhecer a sua essência e aplicação prática. Dos determinantes de custos estruturais empregados merecem destaque a Tecnologia, 
Aplicação do custeio baseado em atividades em uma empresa de serviços rodoviários Edson Roberto Macohon, Jorge Eduardo Scarpin, Wilson Gerigk, Fernanda Castagnolli Domingues, Elvis

empregada em maior escala pelas empresas $A$ e $B$, a empresa $C$, utiliza pouco a tecnologia, isso justifica-se provavelmente em função do tamanho da empresa. A Economia de escala é pouco explorada pela empresa B, com $50 \%$ da capacidade instalada. A empresa B utiliza $70 \%$

Quanto aos determinantes de custos operacionais, merece destaque a preocupação da qualidade, todas as empresas se empenham em garantir a satisfação de seus clientes.

De uma forma geral, as três empresas utilizam determinantes de custos em maior ou menor grau em todos os tópicos. Dessa forma, as empresas empregam os determinantes de custos $100 \%$ dos determinantes de custos analisados na presente pesquisa.

Durante a pesquisa, foi possível observar, também, que apenas as empresas A e $B$, possuem contabilidade de custos internas. A empresa $C$ não percebe a importância dessa ferramenta, talvez devido ao seu porte e sua estrutura de produção ser menos complexa.

\section{CONSIDERAÇÕES FINAIS}

O presente estudo teve por objetivo analisar e descrever determinantes de custo utilizados pelas empresas do setor moveleiro de Araras/SP e Rio Claro/SP. Constatouse que a contabilidade interna de custos ocorre nas empresas $A$ e $B$, provavelmente devido à complexidade e ao porte das empresas, e a empresa $\mathrm{C}$ não tem contabilidade de custo, por desconhecer sua importância.

O termo determinante de custo não é de conhecimento de nenhuma das empresas pesquisadas, porém a utilização ocorre através das experiências adquiridas pelos gestores ao longo do tempo. Detectou-se que as nomenclaturas teóricas dadas aos determinantes de custos não são conhecidas, porém, ao esclarecer durante a entrevista o conceito dos termos de forma clara, ou seja, não contendo termos técnicos, os entrevistados afirmaram sua utilização. Entretanto os determinantes conhecidos pelos entrevistados, não são amplamente explorados conforme a teoria abordada pelos 
Aplicação do custeio baseado em atividades em uma empresa de serviços rodoviários Edson Roberto Macohon, Jorge Eduardo Scarpin, Wilson Gerigk, Fernanda Castagnolli Domingues, Elvis

Fabio Roman

pesquisadores, consequentemente não são utilizados em sua plenitude como ferramenta da gestão estratégica de custos para obtenção da vantagem competitiva.

O presente estudo apresenta contribuição ao comprovar o que foi encontrado na pesquisa realizada por Souza e Mezzomo (2012): "confirma que a aplicação e análise de determinantes de custos de forma inter-relacionada são importantes para gestão competitiva das empresas moveleiras pesquisadas. "Somente um entendimento completo dos determinantes de custos pode ser capaz de fazer compreender o comportamento do custo de uma forma total e ampla que contribua para a formulação da vantagem competitiva.

As empresas pesquisadas utilizam alguns dos determinantes de custos apenas com o objetivo de reduzir custos, sem fazerem uso de um planejamento que adote a teoria da gestão estratégica de custos. Os determinantes de custos estruturais e operacionais, como a tecnologia e a qualidade são os mais utilizados na busca pela redução de custos, já que proporcionam diminuição de mão de obra, redução de perdas na produção e garantia da satisfação do cliente.

Sendo um tema atual e com inexistência de estudos em maior profusão sobre o assunto abordado, sugere-se a realização de pesquisas posteriores que contenham aprofundamentos dos estudos dos determinantes de custos nas empresas.

\section{REFERÊNCIAS}

BARNEY, Jay B. HESTERLY, William S. (2011). Administração estratégica e vantagem competitiva. (3 ed.). São Paulo: Pearson Prentice Hall.

BRIMSON, James A. (1996). Contabilidade por atividades. São Paulo: Atlas.

COSTA, Simone Alves da; CARNEIRO, Diogo Moreira. (2014). Determinantes de custos: uma proposta de taxonomia e agrupamento. XXI Congresso Brasileiro de Custos, Anais... Disponível em: <http://anaiscbc.emnuvens.com.br/anais/article/view/3799>. Acesso em set/2015.

DIEHL, Carlos Alberto; MIOTTO, GenossiRauch; SOUZA, Marcos Antônio. (2010). Análise da tecnologia das aeronaves como determinante de custos no setor de aviação 
Aplicação do custeio baseado em atividades em uma empresa de serviços rodoviários Edson Roberto Macohon, Jorge Eduardo Scarpin, Wilson Gerigk, Fernanda Castagnolli Domingues, Elvis

comercial brasileiro. Revista Brasileira de Gestão de Negócio. São Paulo, v. 12, n. 35, p. 191- 207, abr./jun.

HAYES, Robert. et al. (2008). Produção, estratégia e tecnologia: em busca da vantagem competitiva. Porto Alegre: Bookman.

HITT, Michael A. et al. (2008). Administração estratégica: competitividade e globalização. 2. ed. São Paulo: Cenage Learning.

IUDÍCIBUS, Sérgio de. (1998). Análise de balanços. (7 ed.). São Paulo: Atlas.

Instituto Brasileiro de Geografia e Estatística (IBGE). Disponível em: < Instituto Brasileiro de Geografia e Estatística (IBGE) >. Acesso em 13/set/13.

GIL, Antônio Carlos. (1999). Métodos e técnicas de pesquisa social. (5 ed.). São Paulo: Atlas.

MAÇADA, Antônio G.; FELDENS, Luis F.; SANTOS, André M. (2007). Impacto da tecnologia da informação na gestão das cadeias de suprimentos- um estudo de casos múltiplos Gest. Prod., São Carlos, v.14, n.1, p.1-12, jan.-abr. Disponível em: <http://www.scielo.br/pdf/gp/v14n1/01.pdf>. Acesso em 13/abr/2013

MÁRIO, Poueri do Carmo. (2003). A análise de cadeia de valor como ferramenta de criação de valor: um ensaio sobre a relação entre cost drivers e value drivers. IX Convenção de Contabilidade do Rio Grande do Sul. Gramado. Disponível em: <http://www.ccontabeis.com.br/conv/t14.pdf >. Acesso em 29/mar/2013.

MARTINS, Gilberto de Andrade; THEÓPHILO, Carlos Renato. (2009). Metodologia da investigação científica para ciências sociais aplicadas. (2 ed.). São Paulo: Atlas.

MIOTTO, Genossi R. (2007). Análise da gestão estratégica de custos no setor de aviação comercial brasileiro, UNISINOS. São Leopoldo. <http://www.dominiopublico.gov.br/download/texto/cp050283.pdf> acesso em 30/mar/2013.

OLIVEIRA, Djalma de Pinho Rebouças de. (2011). Planejamento estratégico: conceitos, metodologia e práticas. (29 ed.). São Paulo: Atlas.

PORTER, Michael E. (2004). Estratégia competitiva: técnicas para análise de indústrias e da concorrência. Rio de Janeiro: Elsevier.

PORTER, Michael. (1989). Vantagem Competitiva: criando e sustentando um desempenho superior. (2 ed.). Rio de Janeiro: Elsevier. 
Aplicação do custeio baseado em atividades em uma empresa de serviços rodoviários Edson Roberto Macohon, Jorge Eduardo Scarpin, Wilson Gerigk, Fernanda Castagnolli Domingues, Elvis

Fabio Roman

RECEITA FEDERAL. Lei Complementar 123/2006. Disponível em: $<$ http://www.receita.fazenda.gov.br/Legislacao/LeisComplementares/2006/leicp123.htm $>$. Acesso em 13/set/2013.

RICHARDSON, Roberto Jarry. et al. (1999). Pesquisa Social: métodos e técnicas. São Paulo: Atlas.

SHANK, J. K. GOVINDARAJAM, Vijay. (1997). A revolução de custo: como reinventar e redefinir sua estratégia de custo para vencer em mercados crescentemente competitivos. (8 ed.). Rio de Janeiro: Editora Campus.

SILVA, Christian Luiz. (1999). Gestão estratégica de custos: o custo meta na cadeia de valor. Revista FAE, v.2, p.17-26.

SOUZA, Marcos Antônio de; MEZZOMO, Franciele. (2012). Determinantes de custos em empresas de pequeno porte do setor moveleiro: um estudo em empresas da Serra Gaúcha. Rev. de Contabilidade e Controladoria, Universidade Federal do Paraná, Curitiba, v. 4, n.1, p 131-149, jan/abr.

Data de Submissão: 30/05/2014

Data de Aceite: 01/10/2015 